\title{
Emotional Intelligence and Managerial Effectiveness of Principals in Ogoja Educational Zone of Cross River State, Nigeria: Implication for Counseling
}

\author{
Mary Juliana Ada Georgina E. Okoli \\ Educational Administration and Planning, University of Calabar, PMB 11155, Calabar, Nigeria \\ Department of Guidance and Counseling, University of Calabar, PMB 11155, Calabar, Nigeria \\ Corresponding author: Rev. Sr. Dr. Mary Juliana Ada
}

\begin{abstract}
Emotional intelligence as a predictor of principals' managerial effectiveness in secondary schools in Ogoja Educational Zone of Cross River State was investigated. Two research questions and two hypotheses were formulated to guide the study. Simple random sampling was used to select 20 principals and 160 teachers and administered Emotional intelligence test and teachers' questionnaire. Pearson Correlation analysis was used at 0.05 significance level. There was a significant relationship between emotional intelligence and managerial effectiveness of principals. Principals with high emotional intelligence scored higher than their counterparts with low emotional intelligence. It was recommended that regular workshops and seminars should be organized to develop or improve the level of emotional intelligence of principals.
\end{abstract}

Keywords: Emotional Intelligence, Managerial, Effectiveness and Principal

DOI: $10.7176 / \mathrm{JEP} / 10-27-02$

Publication date:September $30^{\text {th }} 2019$

\section{Introduction}

Parrott (2001) defined emotion as a mental and physiological state associated with a variety of feelings which is outside an individual's conscious control. Eaton and Johnson (2007) suggested that one need not to be a slave to emotions because they can be regulated through reflection and conscious control by applying emotional intelligence. Researchers over the past decades have shown that in every school, there is a positive correction between effective principals and emotional intelligence (Slaski and Cartwwright, (2003); Bradberry and Greaves, (2003), Singh, 2003). Principals with high emotional intelligence tend to perform at a higher level than their counterparts with low emotional intelligence and those who tend to improve or work on their emotional intelligence out perform cohorts who do not (Bradberry and Greaves, 2003).

Emotional intelligence is a person's ability to recognize personal feelings and those of others and to manage emotions within themselves and in their relationships with others (Coo, 2006). Emotional intelligence is the ability to sense, understand and effectively use the power of emotions to guide, motivate and even persuade other people. Emotional outbursts in the school environment can negatively affect the school in terms of productivity, representation and profitability.

The concept of emotional intelligence did not attract much attention until when Gardner (1983) broadened and popularized the construct of intelligence through publication of the theory of multiple intelligence. He argued that success in life was not dependent on intelligence quotient alone. He explained that there were seven different types of intelligence namely linguistic, logical, spatial, musical, kenesthetic, intrapersonal and interpersonal intelligence. The term emotional intelligence was coined by Salovey and Mayer (1990) which they defined as the ability to monitor one's and others feelings' and emotion to discriminate among them and to use these information to guide one's thinking and actions. However, the term emotional intelligence inter the mainstream only with Goleman (2004) who is said to be the founder of emotional intelligence. He defined emotional intelligence as the capacity to recognize our own feelings and how to motivate and manage emotions of other people especially in our daily relationships (Goleman, 2001 \& Keshni, 2010) added to Goleman's definition of emotional intelligence by describing it as the ability to sense, understand and effectively apply the power and acumen of emotions as a source of human energy, information and influence to manage human relationship effectively.

Khalili, (2009) looked at the concept of emotional intelligence as an umbrella term that captures a broad collection of individual skills and disposition by describing these skills as soft skills or inter and intra-personal skills that are outside the traditional areas of specific knowledge, general intelligence and technical or professional skills. Fresman and Rubino (2002) clarified that for centuries, philosophical and religious texts have been attempting to focus humanity on the importance of developing awareness and monitoring behavior. They further added that inter personal and intra-personal skills such as compassion, empathy, trust, self-knowledge, observation and contemplation have been reflected on throughout written history.

Over the past several years, numerous studies in the business sector and school system have focused on the 
effect of emotional intelligence on management effectiveness. Goleman (2001) pointed out that research on management strongly suggest that the emotional intelligence of leaders matters twice as much as that of their cognitive abilities such as intelligence quotient (IQ) or technical expertise. Other research findings indicated that leaders who are stronger and higher in emotional intelligence are more likely to succeed and score higher in an emotional intelligence text than those with weak or low emotional intelligence (Cherniss, 2003). While making a contribution in the same field, Bradberry and Graves (2003) stated that leaders who had high emotional intelligence were $20 \%$ more productive than those with low emotional intelligence. On like IQ, emotional intelligence can be enhanced through training (Slaski and Carwright, 2003). In the field of education, Goleman (2004) elaborated that a principal's ability to understand, identify and empathize with educators emotions and then react appropriately are integral factors which could help foster a feeling of job satisfaction amongst educators. Hay (2004) explained that emotional intelligence include both understanding people and doing something without understanding.

Emotional intelligence comprises four competences which include: (A) Self awareness, that is the ability to accurately perceive one's emotions and remain aware of them as happen, including the ability to manage one's response to specific situations and people. (B) Self management is the ability to be aware of one's emotions and have the flexibility to positively direct one's behavior in response to those emotions, to manage emotional reaction in all situations and with all people. (C) Social awareness is the ability to accurately identify the emotion of other people and thus understanding the effects of those emotions, that is, to understand what other people are thinking and feeling even though the perceiver does not feel the same way. (D) Relationship management is the ability to use awareness of one's own emotions and those of others to successfully manage interactions, that is, to provide clear communication and effectively handle conflict (Bradberry and Graves, 2003). Goleman, Boyatzis and McKee (2001) stated that the above competencies of emotional intelligence enable leaders to be aware of their own emotional make-up. This awareness in turn make leaders sensitive and inspiring to others in dealing with emerging issues. In support of this, Hay (2004) explained that emotional intelligence include both understanding people and doing something with that understating. Nzomo (2012) maintained that principals of schools are the chief executives of the institutions the head and are required to provide leadership in all matters related to the running of schools.

Successful schools have a clear sense of direction and are supported by principals who are effective instructional managers. At the secondary school level, principals are the educational leaders in promoting the success of all students and teachers' effectives in carryout their teaching responsibility through collaboration with all stake holders in education and implementation of learning program (Nzomo, 2012). Management is a process of influencing others to understand and agree on what needs to be done effectively and the process of facilitating individual and collective effort to accomplish shared objectives (YUKI, 2002). A wide diversity of approaches to schools management by principals has been proposed, from analyzing who principals are, what they do, how the motivate their teachers, how their style interact with situational conditions and how they can make major changes in their schools (YUKI, 2002). Feelings and moods have been shown to influence the judgment principals make, attributions for success and failure, and inductive or deductive reasoning. It is likely that feeling plays an important role in school management. These emotion/mood capabilities have been addressed by emotional intelligence. Emotional intelligence describes the ability to join emotions and reasoning, using emotions to facilitate reasoning and reasoning intelligently about them (Cook, 2006).

Purpose of the study: The study seeks to achieve the following:

1. To determine the degree of relationship between principals emotional intelligence and their managerial effectiveness.

2. To determine the degree of relationship between main texts scores of principals with high emotional intelligence and their counterparts with low managerial intelligence.

\section{Research Questions}

The following research questions were raised for the purpose of the study:

1. What is the degree of relationship between principals' emotional intelligence and their managerial effectiveness?

2. What is the degree of relationship between main texts scores of principals with high emotional intelligence and their counterparts with low managerial intelligence?

\section{Research Hypotheses}

The following hypotheses were generated for the purpose of this study:

Ho1. There is no significant relationship between principals' emotional intelligence and their managerial effectiveness?

Ho2. There is no significant relationship between the main texts scores of principals with high emotional 
intelligent and their counterparts with low emotional intelligence?

\section{Research design}

The study used descriptive survey research design to collect data from teachers in order to ascertain the degree of relationship between the level of principals' emotional intelligence and their managerial effectiveness in Ogoja Educational Zone of Cross River State, Nigeria

\section{Population of the study:}

The population of the study consisted of all the principals and teachers of the senior secondary schools in Ogoja Educational Zone. The population is therefore made up of 79 principals and 520 teachers.

\section{Sample and sampling technique:}

The sample of 20 principals and 160 teachers were selected from the total population using simple random sampling technique.

\section{Instrument for Data Collection:}

The study made used of two instruments. The instruments were the emotional intelligence test and teachers' questionnaire. The emotional intelligence tests consisted of 15 items used to ascertain the level of emotional intelligence among the principals. The teachers' questionnaire contains 20 items questionnaire and it was used to obtain data from the teachers on the emotional intelligence and managerial effectiveness of their principals.

\section{Method of Data Collection and Analysis:}

The researcher administered the emotional intelligence test personally to the principals and the questionnaire to the teachers for the purpose of generating data for the study. All the hypotheses were tested using the Pearson Product Moment Correlation at the significance level of 0.05 .

\section{Result:}

Table 1: EMOTIONAL INTELLIGENCE TEST SCORE OBTAINED BY THE PRINCIPALS

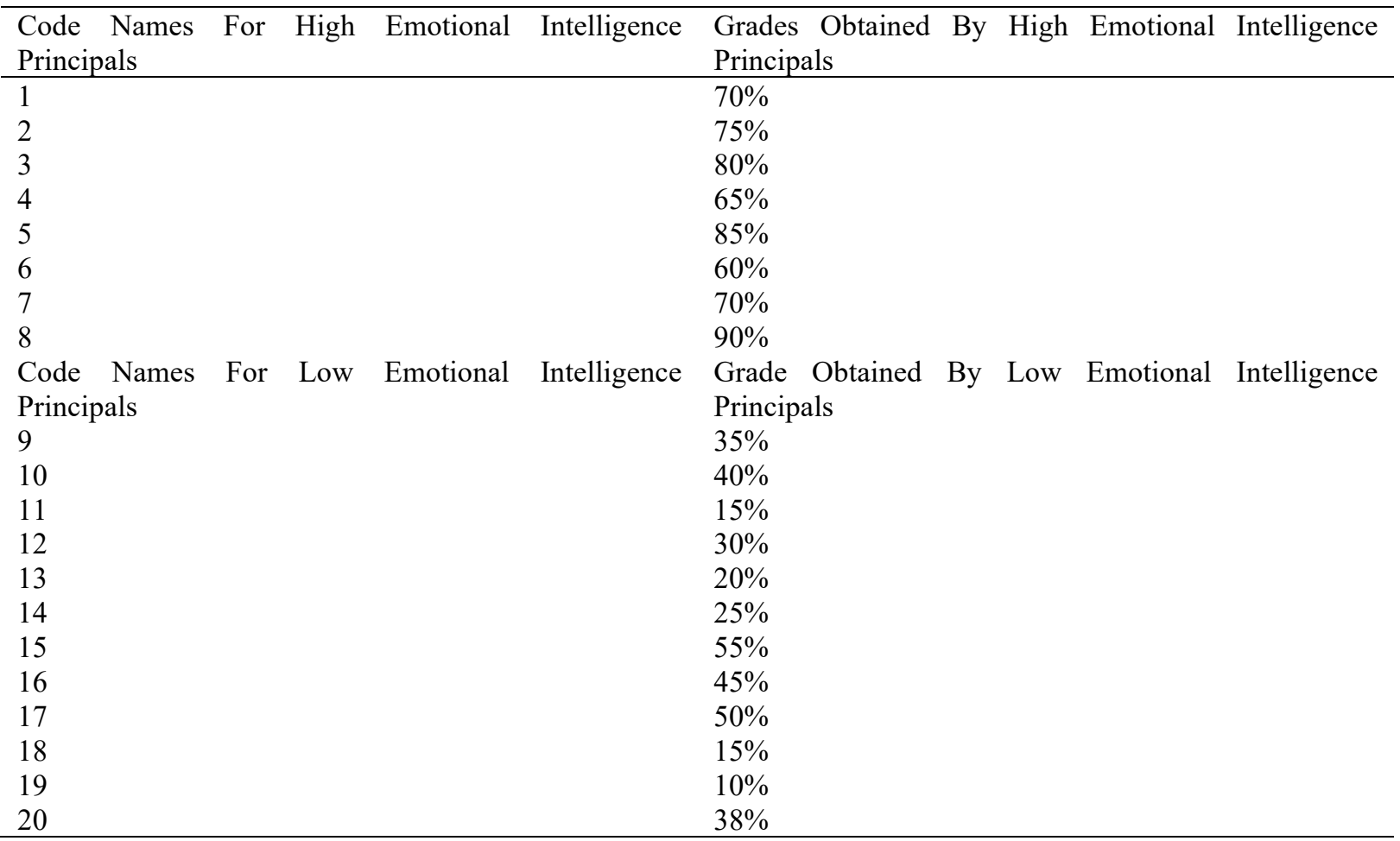


Table 2: Test of significance showing the degree of relationship between principals' emotional intelligence and their administrative effectiveness.

\begin{tabular}{|c|c|c|c|c|c|c|}
\hline $\mathrm{S} / \mathrm{N}$ & $\begin{array}{l}\text { Variables } \\
\text { Decision }\end{array}$ & $\mathrm{DF}$ & $\mathrm{N}$ & $r$ & t-calculated & t-critical \\
\hline 1 & $\begin{array}{ll}\text { Emotional } & 158 \\
\text { Intelligence } & \end{array}$ & 160 & 0.51 & 7.45 & 1.96 & Significant \\
\hline 2 & $\begin{array}{l}\text { Administrative } \\
\text { Effectiveness }\end{array}$ & 160 & & & & \\
\hline
\end{tabular}

Table 1 indicate the test of significance for determining the degree of relationship between emotional intelligence and administrative effectiveness of the principals. The results show that the calculated r-value is given as 0.05 . the $t$-value ( $\mathrm{t}$-calculated) of significance is given as 7.45 which is higher than the critical value of $t$ at 0.05 level or significance, hence, hypothesis 1 is rejected indicating a significant relationship between emotional intelligence and managerial effectiveness of the principals. Hypothesis 2: There is no significant relationship between the mean test scores of principals with high emotional intelligence and their counterparts with low emotional intelligence.

Table 3: Test of significance showing the degree of relationship between the mean tests scores of principals with high emotional intelligence and their counterparts with low emotional intelligence.

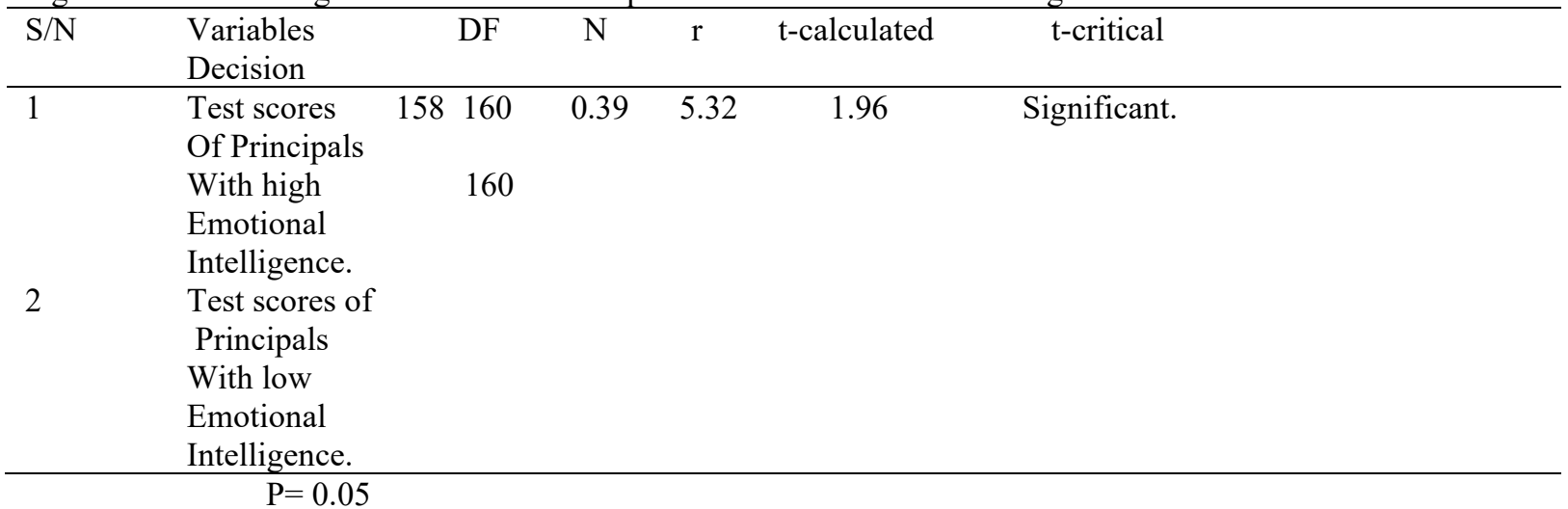

A result from table 3 indicates that the value of $r$ (correlation) is 0.39 . This indicate a low positive correlation. The value from test of significance is given as 5.32 which is greater than the t-critical value which stood at 1.96. Hence, hypothesis 2 is rejected which shows that there is a significant relationship between test scores of principals with high emotional intelligence when compared to their counterparts with low emotional intelligence.

\section{Discussion}

The finding of the study showed that there was a significant relationship between principals' emotional intelligence and their managerial effectiveness. The result showed that the level of principals' emotional intelligence influence their managerial effectiveness in the school system. This means that a principals managerial effectiveness depends on his or her emotional intelligence ability. The finding of the study is in conformity with the views of Slaski, and Cartwright, (2003), Bradberry and Geaves, (2003), Singh, (2003) who observe that there is a positive correlation between effective principals and emotional intelligence.

The finding of the study also showed that there is a significant relationship between the lest scores of principals with high emotional intelligence and their counterparts with low emotional intelligence. This implies that the level of emotional intelligence of the principal influence their performance in an emotional intelligence test. In this regards, principals with high emotional intelligence score higher in the emotional intelligence test administered to them by the researcher than their counterparts with low emotional intelligence. See appendix 1 for details of the results of the emotional intelligence test administered to the principals. These findings confirmed the study by Cherniss, (2003) when he maintained that leaders who are stronger and higher in emotional intelligence are more likely to succeed and score higher in an emotional intelligence test than those with weak or low emotional intelligence.

The findings of this study therefore indicate that principals level of emotional intelligence determines the success they will record in terms of their managerial effectiveness in the school system.

\section{Conclusion}

The ability to recognize one's own emotions and identify how others are feeling requires attention to multiple internal and external cues and the analysis of both verbal and non verbal communication in oneself and others. 
Devoting adequate time and attention to fostering such emotional awareness is extremely important in optimizing principals managerial effectiveness in multiple domains. When principals are able to recognize how they are feeling on daily basis in different situations, they may better express themselves in and out of the school environment. Emotional self-awareness also helps to predict emotions in various circumstances and guide one's behavior. Likewise, the ability to accurately assess the emotions of others can be used to guide the approach a principal may take to address certain activities, such as the appropriate coordination of parent-teacher meetings, daily interactions with teachers, non-teaching staff, students and meetings with officials of ministry of education.

\section{Recommendations}

Based on the findings of this study, the following recommendations are made towards effective integration of principals' emotional intelligence and their managerial effectiveness in the secondary school system:

The government should helps in the improvement and development of emotional intelligence of the principals by organizing workshops, seminars, symposia and lectures on regular basis for them. This will help the principals to acquire emotional intelligence skills that will promote their managerial effectiveness in the school system. It also recommended that before promoting a teacher to the position of a principal, such a teacher should be properly assessed through emotional intelligence test to determine the level of his or her emotional intelligence. This will help to subject teachers with low emotional intelligence to be trained before assuming the position of principal.

\section{Counseling Recommendations}

Emotional intelligence is an important predictor of performance in organizational social personal, academic and other domain. Researchers have constantly reiterated the role of emotional intelligence as a correlate of life satisfaction psychological wellbeing and occupational success and job performance.

Emotional Intelligence is the ability to understand and manage emotion, improving emotional capacity can help a person reduce mental health symptoms. A high emotional Intelligence can also reduce tendencies towards aggression and quicken recovery from traumatic events. The right therapist can help individuals improve their emotional intelligence and their overall well being. Therapy can be helpful when a person wishes to better understand and further develop emotional Intelligence. In Therapy individual can improve ability to recognize and understand their own emotions. As they become more mindful of their feelings, they can practice responding to those emotions productively for example, rather than lasting it out when angry, a person can sport their frustration as it grows and take steps to calm down before speaking.

Self awareness can also play a major role $\mathrm{n}$ emotional intelligence. Therapist should from individuals on empathic skills; individuals should become aware of what others around them are feeling. In therapy a person may learn social skills such as reading facial expressions or adjusting their own body language. A therapist may also help individuals practice " small talk in a safe judgment. Free zone Emotional Intelligence training can be especially helpful to persons with as pergeps syndrome

\section{References}

Bradberry, T.R. and Greaves, J.M, (2003). The emotional intelligence appraisal, Technical Manual.. San Diego: TalentSmart.

Cherniss, C. (2003). The business case for emotional intelligence. Retrived October 20, 2015, from the consortium for research on emotional intelligence in organizations: http://www.eiconsortium.org/research/business case for eihtm

Cook, C.R. (2006). Effects of Emotional intelligence on principals' leadership and performance. Montana state University

Eaton, J. and Johnson, R. (2007). Communicating with emotional intelligence, Mumba: Jalo Publishing House.

Freshman, B. and Rubino, L. (2002). Emotional intelligence: A core competency for health care administrators. Health care management $20 \quad$ (4), 1-9. Retrieved October 2015 from http:www.ncdinlm.nih.gov/pubned/12083171.

Gardner, H. (1983). Frames of Mind: The theory of multiple intelligences. New York Basic Books.

Goleman, D. (2004). Emotional intelligence and working with emotional intelligence. London: Bloomsbury.

Goleman, D. (2001). Emotional intelligence: Issues in paradigm building. In C. Cherniss and D.Goleman (Eds.) The emotionally intelligent workplace (pp. 13-26). San Francisco: Jossey Bass.

Goleman, D, Boyatzis, R. and McKee, A. (2001). Primal Leadership: The hidden driver of great performance. Harvard Business Review, 42-51.

Keshni, B. (2010). The emotional intelligence of the principal is essential in the leadership of a functional school. The international Journal of Learning, (15) 10.

Khalili, A. (2009). Gender differences in emotional intelligence among employees of small and medium enterprise: An Empirical Study. Journal of Managerial Sciences. (2)2 
Mayer, J.D, Salovey, P. and Caruso, D.R. (2000). Models of emotional intelligence. In R. J. Sternberg (Ed.) Handbook of intelligence. Cambridge, England: Cambridge University Press.

Nzomo, L.N. (2012) Relationship between principals' emotional intelligence and students' Learning Achievements in Public Secondary Schools in Nairobi County, Kenya Lydi: A Thesis Submitted to the School of Education in Fulfillment of the Requirements for The Award of the Degree of Doctor of Philosophy of Kenyatta University.

Parrot, W.G.S (2001). Emotions in social psychology. Philadelphia PA: Psychology Press.

Salovey, P. and Mayer, J. D. (1990). Emotional intelligence. Imagination, cognition, and personality. Retrieved December 2011, from http: //www.unh.edu/emotional intelligence/EI/Reprint Proper/E11990 Emotional Intelligence. Pdf.

Slaski, M. and Cartwright, S. (2003). Emotional intelligence training and its implications for stress, health and performance stress and Health: Journal of the International society for the Investigation of Stress, 19 (4), 233-239.

Yukl, G. (2002). Leadership in organizations, (5 ${ }^{\text {th }}$ ed). New York: Prentice-Hall. 